This item was submitted to Loughborough's Research Repository by the author.

Items in Figshare are protected by copyright, with all rights reserved, unless otherwise indicated.

\title{
Operationalisation of service innovation: a systems thinking approach
}

PLEASE CITE THE PUBLISHED VERSION

https://doi.org/10.1080/02642069.2017.1411480

\section{PUBLISHER}

(c) Taylor \& Francis

\section{VERSION}

AM (Accepted Manuscript)

\section{PUBLISHER STATEMENT}

This work is made available according to the conditions of the Creative Commons Attribution-NonCommercialNoDerivatives 4.0 International (CC BY-NC-ND 4.0) licence. Full details of this licence are available at: https://creativecommons.org/licenses/by-nc-nd/4.0/

\section{LICENCE}

CC BY-NC-ND 4.0

\section{REPOSITORY RECORD}

Jaaron, Ayham A.M., and Chris Backhouse. 2019. "Operationalisation of Service Innovation: A Systems Thinking Approach”. figshare. https://hdl.handle.net/2134/27715. 


\section{Operationalisation of Service Innovation: A Systems Thinking}

\section{Approach}

This paper initializes an effort to explore the impact of an innovative systems thinking approach for service operations design on creating innovation. A qualitative exploratory case study approach in two of the UK's service sector departments was conducted, using face-to-face semi-structured interviews, focus groups, and extractions from both observations and documents. The results identify that operationalising service innovation is positively linked with applying the Vanguard Method for service operations design. Twelve micro-determinants for service innovation operationalisation have been identified that reside at three different levels in the service organisation, namely employees level (i.e. Micro), the functional level (i.e. Meso), and corporate level (i.e. Macro). The value of this paper is the introduction of a step-by-step guidance on how to build service operations design to operationalise service innovation, the paper also theorizes service innovation with systems thinking methodology that emphasizes holistic, multi-disciplinary, and integrative characteristics of the service system.

Keywords: service operations; service innovation; service design; design thinking; innovation; service sector; systems thinking; operations management.

\section{Introduction}

Nowadays, services are reconfiguring the global economic arena as they dominate the economies of vast majority of not only most developed nations but also many developing countries (Yen et al., 2012; Hidalgo and D’Alvano, 2014). For instance, services constitute 77\% of the gross domestic product in Australia (O’Cass et al., 2013), $80 \%$ in the United States where services employ more than $80 \%$ of the working population (Cadwallader et al., 2010). In addition, a long-term focus on services growth has been mandated by many countries such as China (Yen et al., 2012) and European countries (Vergori, 2014). In this challenging business environment, delivering a quality service is no longer enough to retain customers and maintain competitive advantage. 
Instead, service organisations must continuously seek to innovate their service operations and offerings, through customer involvement, to deliver high-value services to stay ahead of rivals (Bettencourt et al., 2013; Snyder et al., 2016). As a result, service innovation has become a major catalyst for providing a timely response to customers with entirely new or improved service solutions (Verma and Rajagopal, 2013). It is as conjectured by Chen et al. (2016), market-linking capabilities, such as service channels, must sense external market requirements in order to innovate in their service offerings. This type of innovation is only realised when new operational business concepts, based on intense interactions with customers, are deployed. However, several previous empirical studies suggest that majority of service innovation initiatives are likely to fail without sustainable customer-centric models of service operations (Noble and Mokwa, 1999; Walker et al., 2002; Cadwallader et al., 2010; Andreassen et al., 2016). According to Hogan et al. (2011), although there is a strong emphasis on the ability of service departments to create innovation in the form of management processes and customised offerings and solutions, adequate service operation design-thinking, that can enhance innovation capability through effective deployment of organisational assets, are missing. Indeed, the lack of insight on how service organisations can design their operations to enable service innovation is noteworthy (Vickery et al., 2003; Yen et al., 2012; Ping-Kuo, 2015). This is particularly true when one considers the paucity of strategies for designing and executing innovative customer-focused service operations (Cadwallader et al., 2010). According to Andreassen et al. (2016), service operations design based on customer demand is regarded as "a critical mindset that organizations need to master in order to innovate successfully”. Similarly, Ostrom et al. (2010) asserted that service operations design and innovation currently constitute a top priority in operations management research. Yet few studies have critically investigated the 
nature and viability of such designs (Verganti, 2009; Sanders and Stappers, 2008; Jevnaker et al., 2015). For all that, service operations design is emerging as a response to service sector's need to improve innovation (Jevnaker et al., 2015). The headwind of these pressures on service organisations is posing fundamental questions about the features of the design-thinking model needed. The challenge is, therefore, to investigate how, and what form of, service operations design facilitates and operationalises service innovation in organisations. This paper initializes an effort to explore the impact of an innovative systems thinking approach for service operations design on creating innovation in services. This approach is introduced by Seddon (2003) in his book "Freedom from Command and Control: A Better Way to Make the Work Work". The term "the Vanguard Method" will be used to describe this service operations design model throughout this paper. For this purpose, the following research question has been posed in this paper:

RQ. What impact does the Vanguard Method of systems thinking for service operations design have on operationalizing service innovation?

This paper attempts to demonstrate that the Vanguard Method is a mechanism that is likely to enhance service innovation capabilities by promoting twelve microdeterminants for service innovation that reside at three different levels in the service organisation, namely employees level (i.e. Micro), the functional level (i.e. Meso), and corporate level (i.e. Macro). The paper draws on a qualitative exploratory case study approach in two of the UK's service sector departments that have implemented the Vanguard Method. The rationale behind this design is that case studies can provide an in-depth understanding into little-studied phenomena, such as the Vanguard Method impact on service innovation, within a real-life context (Yin, 2009). The paper contributes to service innovation literature by theorizing service innovation with 
systems thinking methodology that emphasizes holistic, multi-disciplinary, and integrative characteristics of the service system. This linking with systems thinking methodology also adds to literature by articulating a structured process of identifying or learning about a complex customer needs situation leading to deliberate employees’ actions to achieve service innovation. Further, while current methodologies to service operations design confine innovation thinking by only focusing on improving current offered solutions; that is, they assess service offerings that have already been used (Bettencourt et al., 2013), this paper introduces a methodology for service operations design through which inventing new ways of service solutions is achieved by focusing on the job that customers are trying to get done. The paper also contributes to literature by explaining how front-line employees are the main source of innovation realisation; paying attention to the offerings of the Vanguard Method that facilitates front-line employees' contribution to service innovation.

The paper begins by reviewing the literature on concepts of service innovation and service design. Next, the philosophy of the Vanguard Method is outlined with a focus on its implementation principles. Thereafter, the research methodology is explained, and the case studies are presented. Finally, results are shown and conclusions discussed.

\section{Conceptualising Service Innovation}

The concept of service innovation has expanded over the last decade, yet our understanding of service innovation is still blurred (Agarwal and Selen, 2011; Hu, et al., 2012). Service innovation is widely defined as "the introduction of novel ideas that focus on services that provide new ways of delivering a benefit, new service concepts, or new service business models through continuous operational improvement” (Enz, 
2012, p.187). Toivonen and Tuominen (2009, p.893) explain that service innovation is "a new service or such a renewal of an existing service which is put into practice and which provides benefit to the organizations that have developed it; the benefit usually derives from the added value that renewal provides the customers”. Similarly, Ostrom et al. (2010) define service innovation as the process of creating "value for customers, employees, business owners, alliance partners, and communities through new and/or improved service offerings, service processes, and service business models”. These definitions suggest that service innovation include changes to multiple aspects in the organisation such as service delivery processes, service models, and employees’ management (Schaarschmidt, 2016). According to Yen et al. (2012), managing these various dimensions could make the service innovation effort more complex. This highlights the significant role of service design to improve service innovation (Yang and Sung, 2016). The complexity of service innovation is asserted by Evardsson and Olsson (1996). They explain that service innovation is a complex process composed of four overlapping phases. These are the idea generation phase, the project formation phase of planning transferring the idea into reality, the design phase of the new service, and the implementation phase. This is consistent with the work of Sundbo (2008) who presents a three-phase model for service innovation; idea generations phase based on involving actors in the service, development phase of improving the idea to become a usable service, and implementation phase of launching the service into the market. Jong et al. (2005) indicate that successful innovation implementation in service organisations must go through idea generation, screening, evaluation, development, testing, and launching as essential activities. While these scholars suggest, to some extent, overlapping of service innovation development phases, others argue for a more sequential models (Gebauer et al., 2008). Toward that end, service innovation 
complexity seems to require an organisational mechanism that is capable of combining and mobilising new and existing resources to facilitate service innovation (Yen et al., 2012).

Taking into account the increasing importance of creating service firms’ internal innovative climate (Kandampully, 2002); Gebauer et al. (2008) examine the antecedents of service innovation in a manufacturing context. They indicate that involvement of front-line employees, in the form of multifunctional teams where information and knowledge are shared, is one of the most important determinants for the success of service innovation projects. Their results are congruent with those of Cadwallader et al. (2010) who find that front-line employee motivation and participation in service innovation is especially important, as creating innovation is highly dependent on the actions of front-line employees. In contrast, Bettencourt et al. (2013) argue that service firms must expand their focus beyond internal involvement of front-line employees to embrace principles of actively involving customers in the process of creating service innovation. According to authors, this can only be done through addressing customers' fundamental demands and needs into service operations design. Additionally, de Bretani (2001) describe that viewing customers as potential partners, creating an innovative corporate culture, and investing in creating knowledge on customer needs with the help of the customers themselves is central to the service innovation performance. It is as delineated by Bettencourt et al. (2013), “what companies need is an approach to innovation that enables them to identify opportunities for breakthrough service offerings”. Having this perspective, it would seem significantly important to build service operations that combine both outside-in mode of working and empowered multifunctional teams. However, a comprehensive conceptualisation of service innovation is articulated by Lusch and Nambisan (2015) as, first, a collaborative process 
occurring in an actor-to-actor network. Second, the application of specialised competencies for the benefit of the self or the actor in the service and that those competencies are the basis of all service exchanges. Third, resource readiness and resource integration in the service system is the fundamental way to innovate.

\section{Linking service innovation and design thinking}

Today, it is evident that more and more organisations are adopting service-dominant logic that is spurring the rise of service design and design thinking to improve service innovation (Stickdorn and Schneider, 2010; Andreassen et al., 2016; Yang and Sung, 2016). Mager (2009) defines service design as the process of planning and organising people, communication, and material components of a service within responsive operations to improve service quality and the interaction between service provider and customers. In this context, the core of service design, termed design thinking, is the process of using designer's sensibility and methods to match customer's demands with what is technologically feasible and what a viable business strategy can convert into customer value (Brown, 2008). Design thinking is, therefore, not only a way to create effective and efficient solutions for organisations, but also to create value for customers through designing experience-centric services (Zomerdijk and Voss, 2010). WetterEdman et al. (2014) reveal that design thinking of services is heavily interlinked with establishing methods to incorporate customer demands into the service offering that puts the customer first and the service provider second. At more subtle level, Andreassen et al. (2016) summarises three main aspects for design thinking. First, identification of all participants in the process of enabling and using the service; second, understanding customers' demands and wants and linking this with the broader service system and context of use; third, representation of the service through the use of techniques that incorporate all ingredients of the service. In other words, design 
thinking is focused on holistic, multi-disciplinary, and integrative characteristics of value co-creation (Yang and Sung, 2016). This viewpoint is highly related to sustainability of innovation where organisations need to redefine their value and thinking models; by not only focusing on designing solutions for current problems, but also focused on creating a mechanism which empowers employees to continuously respond to customer' demands fluctuations and changes (Sangiorgi, 2011). Triggering innovation out of service design is complex and uncertain (Heim and Ketzenberg, 2011). Service innovation may come from any actor in the service system; where there are a number of them. Innovation may also arise within any of the service activities (Jevnaker et al., 2015). According to Hertog (2000), service innovation may take place during any of the following four stages. First, the service conceptualisation stage where the characteristics of the service are designed; second, the customer contact stage where the service is co-produced with the help of customers; third, service delivery system organisation stage where internal organisational arrangement are made; fourth, technological options stage where innovation is facilitated. In fact, Bettencourt et al. (2013) assert that majority of innovation opportunities are treasured in the customer contact stage; when customers are actually engaged with a service provider.

However, previous research found that service providers are lacking proper service delivery designs that sufficiently support incorporating customer demands and preferences in the service offering; which is necessary for generating innovation (Morelli, 2009; Jevnaker et al., 2015). It is as indicated by Tidd and Bessant (2009), open communication, employee empowerment to make service decisions, and sufficient interactions across organisational boundaries and customers are essential determinants for successfulness of service innovation process, and that is the approach that service organisations should seek to build. These features of the flexible organic structures with 
decentralized decision making authority at the employees' level were found by Tajeddini et al. (2017) as positively associated with the service innovativeness. According to authors, the more the cooperation and dissemination of customer information between the organisation parts, inherited in organic structures, the more the service innovativeness capability.

\section{The Vanguard Method: A systems thinking approach}

The emergence of the field of service science embraces a system approach to model the complexity of service design and service innovation (Chae, 2012; Xing et al., 2013; Andreassen et al., 2016). Seddon (2003) brought out a new design thinking methodology of implementing system thinking principles into service organisations’ operations design, termed here as the Vanguard Method. This methodology is revolving around three core elements: First, interrelationships among the system parts. Second, system dynamics that attempts to understand and describe the changes over time that occur in a system. Third, wholeness which suggests that the whole is greater than the sum of all parts, and that one must view the entire parts of a system operating together in order to understand the dynamics of the system (Seddon, 2008). These core elements are inherited from principles of soft systems methodology developed by Peter Checkland (1981), the systems theory of Ohno (1988), and the intervention theory of Deming (1982). The Vanguard Method articulates a structured process where service operations are strictly built around customer demands and wants, and not around the functional hierarchies or silo working (Jackson et al., 2008). In a complex and dynamic situation, such as designing a service, there are many managers who tend to design several parts of the system separately to provide an overall service solution (Seddon, 2008). Inherently, this will develop a service system where managers need to manage the parts in order to control the whole (Xing et al., 2013). It is as reflected by Yang and 
Sung (2016) the service system is designed for value co-creation that can only be achieved through interacting service system components, and also through openness to interact with the external environment. Therefore, the reductionist approach, defined as building descriptions of a system out of managing system parts separately without understanding the interactions between them (Seddon, 2008), is a main cause for system failure (Ackoff, 1981). This notion is also asserted by Gregory (2007) who explains that silo working is an evident result of the reductionist approach as it hampers necessary interaction in and around the system. Xing et al. (2013) argue that designing a service system based on a connected whole perspective is coherent with design thinking which layout the foundation for service innovation capability. According to Seddon (2003), an organisational culture characterised by the formulation of a multifunctional team capable of managing itself must be in place in order to deliver what the customer wants. In this context, team members are front-line employees from the workplace itself as they will be responsible for leading the Vanguard Method intervention into service operations (Jackson et al., 2008).

Taking a systems view, the team is encouraged to understand the nature of customer demand (Seddon, 2008). This can be achieved by studying the flow of these demands at all point of contact over a considerable amount of time. As the team pursue this logic they learn about different frequencies of demands that the service system has to respond to. This will also allow the identification of two types of customer demands: 'value' and 'failure' demands (Seddon, 2003). Value demands are defined as those demands that the service department is able to deliver and are of value to customers. Failure demands, on the other hand, are defined as those demands caused by a failure to do something right for the customer (Seddon, 2008). According to Jaaron and Backhouse (2017), failure demands are caused by lack of necessary information or 
supporting operations in the service department. This practical starting-place of demand analysis will allow understanding customer demand in customer terms: what matters the most to customers, and what they really expect from the service system. According to Andreassen et al. (2016), this demand analysis methodology allows the service system "to see through the eyes of the customer".

Since the team needs to collectively think, analyse and judge on the nature of demand flow on hands, team members training is not the focus at this stage. It is actually educating them on 'why' a failure occurs and then finding new operational designs to eliminate it from the service system (Seddon, 2008). Therefore, it is critical in this environment that team members are empowered and free to communicate and interact, allowing them to integrate resources into the service encounter, eventually converting them into prime sources of innovation (Lusch and Nambisan, 2015; Karlsson and Skalen, 2015; Jaaron and Backhouse, 2017).

According to Witell et al. (2011), understanding customer perspective on the service is often where innovation opportunities are hidden. During the demand analysis period, team members are capitalising on the knowledge they gain about their customer and capabilities of their service system to educate themselves on "why" a failure happens. Engaging multifunctional teams, this way, will visualise service innovation by delineating new ways to eliminate failures and to deliver what, exactly, the customer is demanding (Jevnaker et al., 2015). Therefore, service systems witness a dramatic shift in the role of managers from being more of a command-and-control to more of supporters-and-helpers. Gebauer et al. (2008), provide a constructive view about the role of top management support as an antecedent for service innovation. According to authors, managers' support encourages service innovation by urging employees to search for new service opportunities that are beyond the scope of existing service 
opportunities. As a result of this type of managers' role and the freedom of team members to change flawed operations, the organisation becomes more innovative (Karlsson and Skalen, 2015).

Figure 1 illustrates a conceptual framework of the Vanguard Method principles when designing service operations. As a first step, efforts are made by the team to understand the purpose of the service system as perceived by the customer. This is usually performed by studying actual customer demands that are received by the service system. During this process, customer demands are analysed over a considerable period of time to find out demand types and frequency of failure demand out of the total demand received. Subsequently, the ability of the system to meet the purpose is identified in terms of the number of value demands delivered to customers during the first contact or visit as opposed to failure demands received. Since value demand is considered as the agreed measure of what matters to customers, the team investigates the capability of service system to deliver against this measure. Thus, in order to improve service system design and reduce failure demands, the team maps the flow of work from the initial receipt of a demand to completion. Therefore, the team constructs a diagram showing all of the various steps and decision points in the flow, including waste identification. In this important stage, all related organisational policies, rules and budgetary requirements, also known as system conditions, are considered. This is particularly important to expose the thinking underlying the way the system is designed before attempting to redesign service operations. Jackson et al. (2008) describe that integrating customer wants and collecting required inputs from all internal business units, during redesigning a service operation, constitute a guarantee that the emerging service operation will be capable of delivering a demand during the first customer contact. 
[Figure 1 near here]

\section{Key processes of the Vanguard Method}

To fully understand how the Vanguard Method approach is applied in practice, this section presents three main steps for the implementation of the Vanguard Method approach in service departments:

1. 'Check' stage: The purpose of the 'check' stage is to study customer demand by collecting information and understanding what matters to customers. This will allow answering the question: what is the purpose of the service system from the customer's point of view? Once this question is answered, a flow of all current processes in the system is mapped to identify waste and systems conditions that stop the flow (Seddon, 2008; Jaaron and Backhouse, 2017). This importance of this stage is the ability to examine, through demand analysis, how capable the current system is in achieving the (real) purpose.

2. 'Plan' stage: This stage involves exploring all possible improvements to the current flow of operations to better achieve the (real) purpose of the service system. A main focus at this stage is the minimization of waste, from a customer's point of view, during the process of mapping out the new service design (Jaaron and Backhouse, 2017). Moreover, this stage involves building new performance measures for the new service design that are based on percentages of delivering value demand out of the total demand received.

3. 'Do' stage: It is at this stage that the new service design is gradually implemented and experimented in the service department. This is achieved through gradual roll-in of front-line employees. It is vital at this stage that customers' feedback 
and employees’ comments on the new service operations are carefully collected and studied to investigate whether the service is providing the (real) purpose of the system. It is expected at this stage that several further improvements are made to the newly designed operations to make sure that customer get the best possible service (Seddon, 2008; Jaaron and Backhouse, 2017).

The process of check-plan-do is a never-ending cycle (see Figure 2) so as to allow for: first, continuous improvement of the system; second, to identify any new demands coming in to the service system that ensures dealing with new demand as value demand; and finally, to allow for designing innovative new service operations when a new idea is generated (Seddon, 2008, Jackson et al., 2008).

[Figure 2 near here]

\section{Research Methodology}

This study employs a qualitative case study research methodology given the exploratory nature of this research. Meredith (1998) argues that case studies are more rigorous and preferred over the traditional rationalist methods used in operations management such as optimization techniques, as they allow analysis of issues from different angles. Therefore, case study research methodology was chosen as the most appropriate method to collect necessary data. This methodology was expected to facilitate in-depth exploration of contextual factors and underlying processes influencing service innovation operationalisation in service organisations as a result of applying the Vanguard Method, and thereby help formulate a thorough conceptualisation of microdeterminants of service innovation. Furthermore, case study research methodology was deemed most appropriate in this research as it has the advantages of being able to answer questions like "what", "how" and "why" (Yin 2009); such as the research 
question type posed at the beginning of this paper. The reason is that the questions of "what", "why", and "how" are typically concerned about the introduction of a comprehensive understanding of operational links in a natural setting, and not the frequency of incidents or events (Kyburz-Graber 2004). In this research, knowledge is required on how the Vanguard Method of systems thinking for service operations design is related to operationalising service innovation, then a survey or an experiment is less likely to provide explanations of how this is done, and it will be more appropriate to conduct a case study in such situation. Yin (2009) explains that carrying out, at least, two case studies can have stronger analytical generalisation from findings, and will produce more valid findings to answer research questions. Therefore, two case studies were chosen for this research inquiry.

\section{Research sites selection and characterisation}

The case study selection process followed the principles of theoretical sampling to expand generalisability prospects of the findings (Gibbert et al, 2008). For this purpose, five service organisations of different industrial sectors and sizes were initially chosen for this type of research post-the Vanguard Method implementation. Subsequently, intensity sampling technique (Miles and Huberman, 1994) has been applied to focus on the cases that exhibit rich or excellent examples of the phenomenon of interest (Yin, 2009). This technique has been deemed most appropriate in this research as authors had prior exploratory work to investigate the variation within the phenomenon under study. This initial exploration allowed the authors to sample relevant intense cases. According to Patton (2004), intensity sampling based on prior information and exploratory works identify intense examples with least bias; as researchers select examples after collecting information on availability of a phenomenon. Thus, the sampling process employed three level criteria for the selection of the most appropriate cases from the five service 
organisations that are long-established around the principles of the Vanguard Method. A candidate service organisation for this research study had to; first, provide qualitative richness and diversity of data from different sources; second, provide access to key informants at all managerial levels that are readily available; third, and most importantly, have been known for its experience in providing innovative offerings and solutions for customers. The application of this sampling criteria resulted in the selection of two service organisations (anonymised). The first case study (i.e. Case A) was carried out at the premises of one of the UK's leading providers of various insurance services. The company started a Vanguard Method intervention in early 2015 that covered all home insurance claims operations. The project was performed through a specially created multidisciplinary team composed of five different teams; traditionally worked in the home insurance department. The traditional teams are general claims team, buildings team, recoveries team, liability team, and payment team. The second case study (i.e. Case B) was carried out at one of England council's service department. The council aimed at creating an environment in which front line workers from different services, whilst retaining their professional and organisational knowledge, powers and links, work together with members of the community itself to take a radical look at the way in which the communities issues can be resolved. This approach relied on complete support from their organisations in clearing the barriers to change and helping to deliver the solutions identified. It was proposed that different services and communities should come together to develop an improved way of working in a place/community and that this design process should use the principles of a systems thinking approach. To make this project a success, the team have developed a series of principles for the way they work. They aim to gain a holistic understanding of the case, assess root causes of the presenting issues and have a different conversation with the resident to see how needs 
can be addressed. Each case is looked at in detail and all systems are interrogated. This was deemed necessary by the team to help build the picture of need and ensures maximum learning from each case. The two case studies are further described in Table 1.

[Table 1 near here]

\section{Data collection}

Qualitative data in this study were collected through face-to-face semi-structured interviews, focus groups, and extractions from both observations and documents collected. Semi-structured interviews were guided by a case study protocol (Yin, 2009) that used inputs from service innovation, design thinking, and the Vanguard Method literature review to formulate interviews' questions. To further enhance validity and relatedness of interviews' questions to available literature, the questions were revised by three academics with extensive background in service innovation and service operations issues. The feedback received was positive. Overall, 18 semi-structured interviews were conducted in the two research sites. Respondents were a mixture of operation managers, service managers, and service team members. The rationale for this mixture of respondents was to reduce the scope of bias inherent in relying on answers provided by one group of people or a small number of respondents. A diverse set of questions were asked to fully investigate the key micro-determinants for service innovation operationalisation in service organisations applying the Vanguard Method. For example, respondents were asked questions such as 'Do you think people at your department are able to solve customers’ problems in very innovative way? Please Explain how?', ‘do you think your organisation management listen to front-line employees if they have new ideas to improve work?', and 'how is sensing of new opportunities/ideas for 
improvement is translated into innovative solutions/services? Is there any process in place to exploit new opportunities?' (See Appendix). Interviews were tape recorded and transcribed in preparation for data analysis. To supplement the data collected through interviews, observations and documents were collected. They helped in capturing things that were not mentioned during interviews and also helped in confirming things that were discussed with respondents. However, the use of focus groups as another main source of data collection was deemed necessary in this research to strengthen and refine the findings of the study. Two focus groups at the size of six and seven employees were drawn from both case study organisations. They were asked to discuss and comment on the preliminary conclusions of the interviews analysis. This step was essential for the final refinement of the analysis and validation of the results (Matthyssens and Vandenbempt, 1998).

\section{Data analysis}

The analysis stage was composed of two sequential processes; the within-case analysis, and then cross-case analysis. The within case analysis started by transcribing the tape recorded interviews before sending them back to respondents for validation, and also as a precaution against misunderstandings (Gibbert et al., 2008). As soon as this process was completed, the transcripts were double-coded following Miles and Huberman's (1994) coding process. Codes were regularly refined and updated throughout the coding process; eventually reaching an inter-coder agreement of almost 90 per cent. At this stage finding codes with common basic themes was carried out. This was done by careful reading of the coded transcripts, which enabled the identification of underlying structures and connections (Attride-Stirling, 2001). To achieve theoretical triangulation, the analysis of interviews was extended to include inputs from focus group discussions, observations, and documents collected from each case study. According to Yin (2009), 
theoretical triangulation, this way, will optimise internal validity and reliability of findings. At this stage, it was possible to extract preliminary sets of service innovation micro-determinants and organisational practices. However, the analysis of each case study was finalised by sharing the results of analysis with the contact person at each case study organisation to maximise empirical validation (Miles and Huberman, 1994). The procedure of cross-case analysis was used for comparisons and pattern matching following the methodological principles of Yin (2009). This step was significantly important to find similarities between the two cases. "Within-category sorting" and “cross-category clustering” techniques have allowed the condensation of cross-case data, and then, eventually, the generation of "summary tables” (Miles and Huberman, 1994). These results are illustrated in Table 2 below. To further categorise the microdeterminants for service innovation found in the cross-case analysis, the tactic of “clustering” (Miles and Huberman, 1994) of micro-determinants was performed by switching sequentially between empirical findings and theoretical inputs; this was very helpful in mapping the distinct micro-determinants identified with the level of organisational structures they are grounded in (see Table 3). This process is known as abduction process (Miles and Huberman, 1994), which is known for its role in ensuring conceptual coherence (Dubois and Gadde, 2002). Finally, the results were then interpreted against related literature to find out how these findings are supported or conflicted with previous studies.

\section{Results}

The data analysis resulted in the following three levels of micro-determinants of service innovation operationalisation in service organisations applying the Vanguard Method. 


\section{Employee level (i.e. Micro level)}

Analysis of the data collected through interviews and focus groups stressed the importance of formulating multifunctional teams for the process of operationalising service innovation. It is revealed that the principle of the Vanguard Method of relocating front-line employees to work within teams has facilitated frequent interaction between employees, which is necessary for knowledge and new ideas sharing. Interviewees at 'Case A' mentioned that front-line employees collect pieces of information from each other, in addition to customers, and use this information in the process of reconfiguring the service operation to deliver what the customer wants, which results in ideas necessary for service innovation. It is as stated by a service manager at 'Case A': "we trust employees and we want them to know they are trusted to work together, discuss things together, and change things together....information sharing is a must in this environment as best service solutions are always made collectively”. Furthermore, building internal competencies of front-line employees were also a fundamental issue in creating innovation. The utilisation of employees' proximity to each other and open communication was found at both case studies to be an enabler for exchanging experiences, especially from those with high levels of knowledge in the service system, to allow for novice employees active involvement in creating innovative solutions for customers. At 'Case B', it was found that multi-disciplinarily of the team was ensured through encouraging open communication and flexibility between frontline employees, to involve different employees from different departments and backgrounds in creating innovation. For example, the multifunctional team at 'Case B' explained a case where multiple reports of Anti-Social Behaviour at a local restaurant were received by police. Four team members with different backgrounds (i.e. AntiSocial Behaviour Specialist, Domestic Abuse Specialist, Adult social care worker, and 
Drugs and Alcohol worker) joined the police to talk to the restaurants' manager. The reports were about a group of young people congregating in and around the premises and causing noise. Talking to manager and young people identified that the young people were only there for the free Wi-Fi. Further investigation revealed that previously they all had gone to library for the free Wi-Fi, but the library was now closed in the evening, and since they have no credit on their phone, and needed access, they congregated in and around the premises. In solving this problem, the team members relied on mapping and engaging the local community by contacting community groups, businesses, and faith groups. It was eventually solved by one of the local companies who sponsored a free Wi-Fi service in the seating area around the library premises. Due to the offerings of this new service operations design, interviewees at both case studies explained that they are now empowered to test variety of ways to creatively solve problems based on collaborative approach. They added that they are now allowed to have more time to look at a demand as the principle of the service design is to deliver demands right, rather than delivering demand quickly.

[Table 2 near here]

[Table 3 near here]

\section{Functional level (i.e. Meso Level)}

In terms of the micro-determinants affecting service innovation at the functional level of operating service departments, all interviewees described that their service innovativeness is strongly linked with identifying the customer's nominal value (i.e. what the customer wants). According to them, new creative ideas, and eventually innovation, can only be discerned by having a free conversation with the customer to explore, in as much as possible, the holistic and complex problematic situation of the 
customer. From the understanding of 'what matters' to service users, it was then possible to translate these new ideas into new service offerings. This fundamental process of having an open conversation with customers included trying to establish future needs of customers through anticipating any predictable changes in circumstances that might occur. A claim handler from 'Case A' commented: "we treat customers as if they are partners in processing their claims, we just keep talking to them until we are satisfied that we have actually understood their current and future world....we believe that involving customer is the best way to continuously renovate our service through the knowledge we collect from them”. Another interesting practice that was linked with generating new ideas for service innovation is related to continuous customer demand scanning. Interviewees showed consensus on the role of continuous demand scanning in identifying operational blockages in the system which were preventing it from delivering what the customer exactly wants, thus providing several innovative ideas on how the systems can be improved. Front-line employees are now expected by their senior managers to continuously monitor demand coming in to the workplace, and question the system operations if demand is recorded as a failure. Managers' role was found by interviewees as a catalyst for employees to participation in searching for opportunities for service innovation. Moreover, results showed that the Vanguard Method supported the principle of one-stop resolution in the service system. To achieve this, the new service design at both case studies allowed front-line employees, with expertise, to collect as clean (i.e. precise) information as possible at the first contact with customers. This, and the ability of front-line employee to pull support when required from his peers, was deemed the best way to understanding the nominal value of customers and to deliver the service at that first contact, or as soon as possible after the first contact. Interviewees stated that this procedural practice was significantly 
important in involving customer in generating ideas for designing the service delivery according to their needs, and it also helped in identifying any mistakes in delivering a service instantly while the customer is engaged. For example, interviewees at 'Case A' shared a case where an old man with insurance cover for glasses fell down the staircase and broke his glasses. Glass fragments went into is eyes and he had to be admitted to hospital. At this stage, getting new glasses was this Oldman's top priority; to be able to see properly after leaving the hospital. After contacting 'Case A' team from inside the hospital and having a thorough conversation, the team arranged for an optician to visit the Oldman in the hospital to get his new glasses made. The glasses were ready and dispatched to the Oldman's house on time when he was discharged from hospital, and then 'Case A' team arranged for the optician payment. Interviewees added that before having the Vanguard Method design, their system response was to request the Oldman to visit an optician himself (which was impossible given his health condition), get a quote, and send it to 'Case A' to pay.

\section{Corporate level (i.e. Macro level)}

The two case studies exhibited aspects of corporate level changes that have informally guided service innovation. Interviewees at both research sites expressed that the Vanguard Method has brought up new values to their working place that are shared by everyone. According to them, the new corporate culture requires employees to be focused on delivering value work to customers. Interviewees regarded this as key for service innovation where service operations are continuously configured and reconfigured to deliver value. They added that their top managers are no longer using pre-set individual target to measure the service systems performance, due to their corporate believe that individuals' performance is governed by the system and not by managerial numbers. Another aspect that has been regarded by interviewees as having a 
substantial effect on determining service innovation is the interdepartmental integration and interaction for the sake of knowledge and information exchange. Interviewees explained that their corporate culture supports departmental interaction that includes teleconferencing, phone calls, meetings, exchange of documents, and partially accessing other departments' IT systems and records. These activities are regarded by interviewees as a necessity to collect vital knowledge for value creation and ideas generation. In 'Case A' knowledge and information sharing was done at two levels; first, transferring knowledge from other departments or divisions to the multifunctional team place through phone calls and IT system utilisation; second, transferring information and recommendations for improvement from the multifunctional team workplace to other related departments based on learning achieved from the system. Operations change and development manager at 'Case A' stated that "other departments are now more able to assist team members, share ideas, information, and even provide feedback to them”. Whereas at 'Case B' knowledge and information sharing was more evident as the multifunctional team has all services working together by sharing one large space, and their IT system was reprogramed to allow some certain type of access for each team member to view related information about residents. However, to reinforce a culture of exploration among employees, it was found that 'Case A' has a bimonthly best idea contest where employees can raise their ideas via a specially created online tool. The contest aims at either defying conventional working operations or creating an innovative service offering. At 'Case B', the council was evaluating his multifunctional team based on their ability to deliver value service of meeting customer demand, and also the ability of team members to come up with new ideas to improve service operations. 


\section{Discussion and Conclusions}

Based on the need for linking service operations design with achieving innovation in service organisations, and due to the urgency of this topic in operations management research (Ostrom et al., 2010; Andreassen et al., 2016), the aim of this study has been on exploring key micro-determinants for service innovation operationalisation in service organisations applying the Vanguard Method for service operations design. The results achieved from cross-case analysis have proven that operationalising service innovation is positively linked with applying the Vanguard Method for service operations design. Twelve micro-determinants for service innovation operationalisation have been identified that reside at three different levels in the service organisation, namely employees level (i.e. Micro), the functional level (i.e. Meso), and corporate level (i.e. Macro). Figure 3 depicts these three different levels in a conceptual model.

[Figure 3 near here]

The results in both cases reveal that the Vanguard Method design has a significant effect at the employees' level (i.e. Micro level). This is particularly true as it was found that front-line employee's role has dramatically changed from, first, working individually to become part of a multidisciplinary team, and second, from mere execution of standardised repetitive steps of service to totally being empowered to owning the service system. This implies that giving front-line employees a voice on what needs to be done and how to do it suggest that new practical ideas will emerge, and will increase possibility of creating innovation. This is supported by the findings of Ordanini and Parasuraman (2011) who indicate that freedom of employees to act on service system enhance the frequency of innovative solutions introduction and radicalness. Furthermore, relocating employees to be part of a team is accompanied by 
significant changes in employees' behaviour to produce new methods of combining and modifying organisational resources to deliver what the customer wants. The employee, in such environment, is expected to develop, or help in developing, new internal procedures to deal with new customer demands. These new procedures are deeply institutionalised in the organisation through sharing them with other employees. Karlsson and Skalen (2015) express that this behaviour of developing novel procedures is a key characteristic of service innovation. Moreover, the ability of employees to collectively generate an idea, develop a new procedure, and the institutionalisation of this new procedure is in congruence of Sundbo's (2008) process of creating service innovation. According to Sundbo (2008), service innovation is a process that navigates through three main distinct phases; ideas generation phase, a development phase, and an implementation phase.

The overall results posit the Vanguard Method design as an antecedent of functional level (i.e. Meso level) micro-determinants of service innovation in both case studies. The service function focus on the customer is prevalent in the Vanguard Method principle of involving customer in the process of designing service operations. This is also deeply rooted in the activities of the service function of continuously analysing customer demand. According to Shah et al. (2006), an organisation can only transform itself to focus on the customer when it successfully changes its processes and structures. However, design thinking logic, inherited in the Vanguard Method principles, emphasizes the introduction of a solution that puts the customer first and the organisation second. Thus, the findings reported here are in line with design thinking logic principles (Andreassen et al., 2016). At a more subtle level, the results suggest that the Vanguard Method design helps customers achieve new solutions that will improve their well-being. Therefore, it can be discerned that the Vanguard Method design uses 
the service innovation process to act as a proxy for customer well-being (Seddon, 2008). In this respect, the results view the role of a service manager as a mediator to make sure that customer needs are well-integrated into the process of developing the service operations, and eventually, the service solution. As such, the role of service manager include; first, securing active partnership with customers to uncover latent opportunities through which new ideas for service improvement can be achieved; second, encourage multifunctional teams to look deeper into customer demands to see if these demands are part of other divisions or processes that can be exploited to create additional improvement opportunities; finally, and most importantly, making sure that these opportunities are translated into real service operations and offerings to materialise innovation. These changes at the service function level are well-supported by the work of Bettencourt et al. (2013) of shifting focus away from service offerings back to customers.

In terms of corporate level (i.e. Marco level) micro-determinants of service innovation, the results suggest that a special type of organisational culture will automatically flourish in the organisation as a whole following the Vanguard Method application. Manning and Bodine (2012) assert that corporate culture changes are impacted by implementing an outside-in mode of working. Thus, the Vanguard Method principle of having an outside-in perspective of service operations design is accompanied by various changes to organisational shared values and beliefs. The results suggest that one of the most prevalent changes to organisational culture is attributed to the focus on customer value creation of delivering what customer exactly wants. According to Andreassen et al. (2016), this working mind-set, of having an outside-in perspective, pervades all stages of the service processes and managerial levels, where capturing new ideas necessary for service innovation becomes the responsibility of 
everyone in the organisation. For this purpose, the results postulate that the outside-in mode of working is enshrined in the organisation practices of having open channels of sharing knowledge and information between departments to facilitate customer service delivery and new operations design. This is in line with the work of Hu, et al. (2012) who found that knowledge sharing is a key factor for promoting service innovation capability. Involving other departments in service innovation practices allows them to contribute to recombining resources and reconfiguring existing links between service system entities; to come up with completely new recipe for service solutions. It is because of these new recipes that front-line employees are evaluated on the basis of how good they are in generating new ideas to improve the system and innovate.

\section{Theoretical Contributions}

The findings of this study have a number of significant contributions for practitioners and researchers. First, this study provides an attempt to explore the impact of an innovative systems thinking approach for service operations design on operationalising service innovation. While previous studies have attempted to link the role of service design and design thinking in the process of enhancing service innovation, those studies neither directly provide clear methodology on how service operations design can be built, nor identify what determinants can be achieved as a result of an adequate service design methodology. For example, Andreassen et al. (2016) develop a framework for understanding service design and how it can relate to enhancing customer experience in

the context of service innovation. However, this study was a pure conceptual attempt that did not pay attention to methodological needs for building a service operation design that can be linked with service innovation achievement. Further, Jevnaker et al. (2015) introduce a designer-assisted and collaborative concept-creating framework for improving innovation experimentation among corporate employees, but this managerial 
framework failed to address managerial learning and involvement and organisationinternal issues necessary for service innovation. The same stands for the work of Yang and Sung (2016) who studied social innovation only using service design tools, without introducing practical guidance on how to design such services in the business sector. Second, while current methodologies to service operations design confine innovation thinking by only focusing on improving existing offered solutions; that is, they assess service offerings that are currently being used (Bettencourt et al., 2013), this paper introduces a methodology for service operations design through which a balance can be achieved between exploitation of existing services that ensure organisation's present survival, and exploration of innovative services that ensure future survival. Third, the paper also contributes to service innovation literature by theorizing service innovation with systems thinking methodology that emphasizes holistic, multi-disciplinary, and integrative characteristics of the service system. This linking with systems thinking methodology also adds to literature by articulating a structured process of identifying or learning about a complex customer needs situation leading to deliberate employees' actions to achieve service innovation. Finally, the paper also contributes to literature by explaining how front-line employees are the main source of innovation realisation; paying attention to the offerings of the Vanguard Method that facilitate front-line employees’ contribution to service innovation.

\section{Limitations and Future research work}

Although the study shows supportive evidence and empirical validation of the findings, there are still some elements that could potentially limit the applicability of these findings. First, guided by a qualitative research methodology, the study identifies twelve micro-determinants for service innovation that form three different levels in the service organisation applying the Vanguard Method. However, findings might have overlooked 
other micro-determinants contributing to the construct of service innovation in such environment. Future research may seek to use different research approaches, such as the grounded theory, to explore any other micro-determinants potentially unidentified in this current study. Second, paucity of previous researches on the topic of service design links with service innovation has limited this study's ability to suggest grounded theory development based on the findings (Cooper and Emroy 1995). Third, data were collected from two case studies representing two different service sectors, the study, therefore, might carry some issues for generalisability. Replicating this study in other service sectors will be necessary to determine the extent to which the findings can be generalised. However, future research may consider using micro-determinants of service innovation identified in this research to developing both; service innovation capabilities and service readiness measuring systems. It would also be interesting for future researchers to check the validity and availability of the identified microdeterminants in non-service context, such as manufacturing firms. Finally, although this paper postulates that service organisations applying the Vanguard Method perform well in creating innovation; future research may consider conducting longitudinal studies to document changes in service innovation intensity patterns due to leadership changes or front-line employees’ replacements.

\section{References}

Ackoff, R.L. (1981). Creating the Corporate Future. New York: John Wiley and Sons. Agarwal, R., \& Selen, W. (2011). Multi-dimensional nature of service innovation Operationalisation of the elevated service offering construct in collaborative service organizations. International Journal of Operations \& Production Management, 31, 1164-1192. 
Andreassen, T.W., Kristensson, P., Lervik-Olsen, L., Parasuraman, A., McCollKennedy’ J.R., Edvardsson, B., \& Colurcio, M. (2016). Linking service design to value creation and service research. Journal of Service Management, 27, 21 29.

Attride-Stirling, J. (2001). Thematic networks: an analytic tool for qualitative research. Qualitative Research, 1, 385-405.

Bettencourt, L.A., Brown, S.W., \& Sirianni, N.J. (2013). The secret to true service innovation. Business Horizons, 56, 13-22.

Brown, T. (2008). Design Thinking. Harvard Business Review, June 2008, 84-92.

Cadwallader, S., Jarvis, C.B., Bitner, M.J., \& Ostrom, A.L. (2010). Frontline employee motivation to participate in service innovation implementation. Journal of the Academy of Marketing Science, 38, 219-239.

Chae, B.K. (2012). An evolutionary framework for service innovation: insights of complexity theory for service science. International Journal of Production Economics, 135, 813-822.

Checkland, P. (1981). Systems Thinking, Systems Practice. Chichester: Wiley.

Chen, K., Wang, C., Huang, S., \& Shen, G.C. (2016). Service innovation and new product performance: The influence of market-linking capabilities and market turbulence. International Journal of Production Economics, 172, 54-64.

Cooper, R.D., \& Emroy, C.W. (1995). Business Research Methods. Fifth ed., Homewood, IL: Richard D. Irwin.

de Brentani, U. (2001). Innovative versus incremental new business services: different keys for achieving success. Journal of Product Innovation Management, 18, 169-87.

Deming, W.E. (1982). Out of Crisis. Cambridge: Cambridge University Press. 
Dubois, A., \& Gadde, L.E. (2002). Systematic combining: an abductive approach to case research. Journal of Business Research, 55, 553-60.

Edvardsson, B., \& Olsson, J. (1996). Key concepts for new service development. The Service Industries Journal, 16, 140-164.

Enz, C.A. (2012). Strategies for the implementation of service innovations. Cornell Hosp. Q., 53, 187-195.

Gebauer, H., Krempl, R., Fleisch, E., \& Friedli, T. (2008). Innovation in product-related services. Managing Service Quality, 18, 387-404.

Gibbert, M., Ruigrok, W., \& Wicki, B. (2008). What passes as a rigorous case study?. Strategic Management Journal, 29, 1465-1474.

Gregory, A.J. (2007). Target setting, lean systems and viable systems: a systems perspective on control and performance measurement. Journal of the Operational Research Society, 58, 1503-1517.

Heim, G.R., \& Ketzenberg, M.E. (2011). Learning and relearning effects with innovative service designs: An empirical analysis of top golf courses. Journal of Operations Management, 29, 449-461.

Hertog, P.D. (2000). Knowledge-intensive business services as co-producers of innovation. International Journal of Innovation Management, 4, 491-528.

Hidalgo, A., \& D’Alvano, L. (2014). Service innovation: inward and outward related activities and cooperation mode. Journal of Business Research, 67, 698-703.

Hogan, S.J., Soutar, G.N., McColl-Kennedy, J.R., \& Sweeney, J.C. (2011). Reconceptualizing professional service firm innovation capability: scale development. Industrial Marketing Management, 40, 1264-1273. 
Hu, M.-L. M., Ou, T.-L., Chiou, H.-J., \& Lin, L.-C. (2012). Effects of social exchange and trust on knowledge sharing and service innovation. Social Behavior \& Personality, 40, 783-800.

Jaaron, A.A.M., \& Backhouse, C.J. (2017). Operationalising “Double-Loop” learning in service organisations: a systems approach for creating knowledge. Systemic Practice and Action Research, 30, 317-337.

Jackson, M.C., Johnston, N., \& Seddon, J. (2008). Evaluating systems thinking in housing. Journal of the Operational Research Society, 59, 186-197.

Jevnaker, B. H., Tellefsen, B., \& Luders, M. (2015). Front-end service innovation: learning from a design-assisted experimentation. European Journal of Innovation Management, 18, 19-43.

Jong, J., Bruins, A., Dolfsma, W., \& Meijaard, J. (2005). Innovation in service firms explored: what, how and why? Literature Review. EIM Business and Policy Research, Zoetermeer.

Kandampully, J. (2002). Innovation as the core competency of a service organisation: the role of technology, knowledge and networks. European Journal of Innovation Management, 5, 18-26.

Karlsson, J., \& Skalen, P. (2015). Exploring front-line employee contributions to service innovation. European Journal of Marketing, 49, 1346-1365.

Kyburz-Graber, R. (2004). Does case-study methodology lack rigour? The need for quality criteria for sound case-study research. Environmental Education Research, 10, 53-65

Lusch, R. F., \& Nambisan, S. (2015). Service innovation: a service-dominant logic perspective. MIS Quarterly, 39(1), 155-175.

Mager, B. (2009). Touchpoint. Journal of Service Design, 1, 20-29. 
Meredith, J. (1998). Building operations management theory through case and field research. Journal of Operations Management, 16, 441-454.

Manning, H., \& Bodine, K. (2012). Out Side In. The Power of Putting Customers at the Center of Your Business. Boston- New York: New Harvest, Houghton Mifflin Harcourt.

Matthyssens, P., \& Vandenbempt, K. (1998). Creating competitive advantage in industrial services. The Journal of Business and Industrial Marketing, 13, 339355.

Miles, M. B., \& Huberman, A. M. (1994). Qualitative Data Analysis: An Expanded Sourcebook, Second ed. Thousand Oaks: Sage Publications.

Morelli, N. (2009, November). Beyond the experience. In search of an operative paradigm for the industrialisation of services. Paper presented at the First Nordic Conference on Service Design and Service Innovation, Conference Proceedings ServDes.2009; DeThinking Service; ReThinking Design, Oslo, Norway.

Noble, C. H., \& Mokwa, M. P. (1999). Implementing marketing strategies: developing and testing a managerial theory. Journal of Marketing, 63, 57-73.

O’Cass, A., Song, M., \& Yuan, L. (2013). Anatomy of Service Innovation: Introduction to the Special Issue. Journal of Business Research, 66, 1060-1062.

Ohno, T. (1988). Toyota Production System: Beyond Large-Scale Production. New York: Productivity Press.

Ordanini, A., \& Parasuraman, A. (2011). Service innovation viewed through a servicedominant-logic lens: a conceptual framework and empirical analysis. Journal of Service Research, 14, 3-23.

Ostrom, A.L., Bitner, M.J., Brown, S.W., Burkhard, K.A., Goul, M., Smith-Daniels, V., Demirkan, H., \& Rabinovich, E. (2010). Moving forward and making a 
difference: research priorities for the science of service. Journal of Service Research, 13, 4-36.

Patton, M.Q. (2004). Qualitative Research and Evaluation Methods. Thousand Oaks, California: Sage Publications.

Ping-Kuo, C. (2015). Impacts of investment attitude in service innovation. Total Quality Management \& Business Excellence, 26, 875-887, DOI: 10.1080/14783363.2014.901802

Sanders, E.B.N., \& Stappers, P.J. (2008). Co-creation and the new landscape of design. CoDesign, 4, 5-18.

Sangiorgi, D. (2011). Transformative services and transformation design. International Journal of Design, 5, 29-40.

Schaarschmidt, M. (2016). Frontline employees' participation in service innovation implementation: the role of perceived external reputation. European Management Journal, 34, 540-549.

Seddon, J. (2003). Freedom from Command and Control: A Better Way To Make The Work Work. Buckingham: Vanguard Education.

Seddon, J. (2008). Systems Thinking in the Public Sector. Axminster: Triarchy Press.

Shah, D., Rust, R. T., Parasuraman, A., Staelin, R., \& Day, G. S. (2006). The path to customer centricity. Journal of Service Research, 9, 113-124.

Snyder, H., Witell, L., Gustafsson, A., Fombelle, P., \& Kristensson, P. (2016). Identifying categories of service innovation: a review and synthesis of the literature. Journal of Business Research, 69, 2401-2408.

Stickdorn, M., \& Schneider, J. (2010). This is Service Design Thinking. Amsterdam: BIS Publishers. 
Sundbo, J. (2008). Innovation and involvement in services. In L. Fuglsang (Ed.), Innovation and the Creative Process: Towards Innovation with Care (pp. 25-47). Cheltenham: Edward Elgar.

Tajeddini, K., Altinay, L., \& Ratten, V. (2017). Service innovativeness and the structuring of organizations: The moderating roles of learning orientation and inter-functional coordination. International Journal of Hospitality Management, 65, 100-114.

Tidd, J., \& Bessant, J. (2009). Managing Innovation: Integrating Technological, Market And Organizational Change. Chichester: Wiley.

Toivonen, M., \& Tuominen, T. (2009). Emergence of innovations in services. The Service Industries Journal, 29, 887-902.

Verganti, R. (2009). Design-Driven Innovation: Changing the Rules of Competition by Radically Innovating What Things Mean. Boston, MA: Harvard Business Press.

Vergori, A.S. (2014). Measuring innovation in services: the role of surveys. The Service Industries Journal, 34, 145-161.

Verma, R., \& Rajagopal (2013). Conceptualizing service innovation architecture: a service-strategic framework. Journal of Transformational Management,18, 3-22.

Vickery, S.K., Jayaram, J., Droge, C., \& Calantone, R. (2003). The effects of an integrative supply chain strategy on customer service and financial performance: an analysis of direct versus indirect relationships. Journal of Operations Management, 21, 523-539.

Walker, R. H., Craig-Lees, M., Hecker, R., \& Francis, H. (2002). Technology-enabled service delivery: an investigation of reasons affecting customer adoption and rejection. International Journal of Service Industry Management, 13, 91-106. 
Wetter-Edman, K., Sangiorgi, D., Edvardsson, B., Holmlid, S., Grönroos, C., \& Mattelmäki, T. (2014). Design for value co-creation: exploring synergies between design for service and service logic. Service Science, 6, 106-121.

Witell, L., Kristensson, P., Gustafsson, A., \& Löfgren, M. (2011). Idea generation: customer cocreation versus traditional market research techniques. Journal of Service Management, 22, 140-159.

Xing, K., Ness, D., \& Lin, F. (2013). A service innovation model for synergistic community transformation: integrated application of systems theory and product-service systems. Journal of Cleaner Production, 43, 93-102.

Yang, C., \& Sung, T. (2016). Service design for social innovation through participatory action research. International Journal of Design, 10, 21-36.

Yen, H., Wang, W., Wei, C., Hsu, S., \& Chiu, H. (2012). Service innovation readiness: dimensions and performance outcome. Decision Support Systems, 53, 813-824.

Yin, R. (2009). Case Study Research: Design and Methods. Thousand Oaks: Sage Publications.

Zomerdijk, L.G., \& Voss, C.A. (2010). Service design for experience-centric services. Journal of Service Research, 13, 67-82. 


\section{Appendix}

\section{Interview Questions:}

Q1) how was the work done before implementing the Vanguard Method? How is it currently being done?

Q2) would you like to tell us about the benefits that the Vanguard Method has brought to your services/operations? At personal and operational levels?

Q3) do you think your department is able to create innovative services that offer unique benefits for your customers? Why? Any examples?

Q4) do you think people at your department are able to solve customers' problems in very innovative way? Please Explain how?

Q5) do you think your organisation management listen to front-line employees if they have new ideas to improve work?

Q6) how is this sensing of new opportunities/ideas for improvement is translated into innovative solutions/services? Is there any process in place to exploit new opportunities?

Q7) how is your service system is reconfigured to implement new ideas?

Q8) does your organisation collect information from all parts of the organization when solving problems or improving systems?

Q9) do you think technology constitutes an essential part of your service innovation capability? Explain How?

Q10) if you think your organisation is more innovative capable organisation now, as a result of implementing the Vanguard Method, why do you think so? 


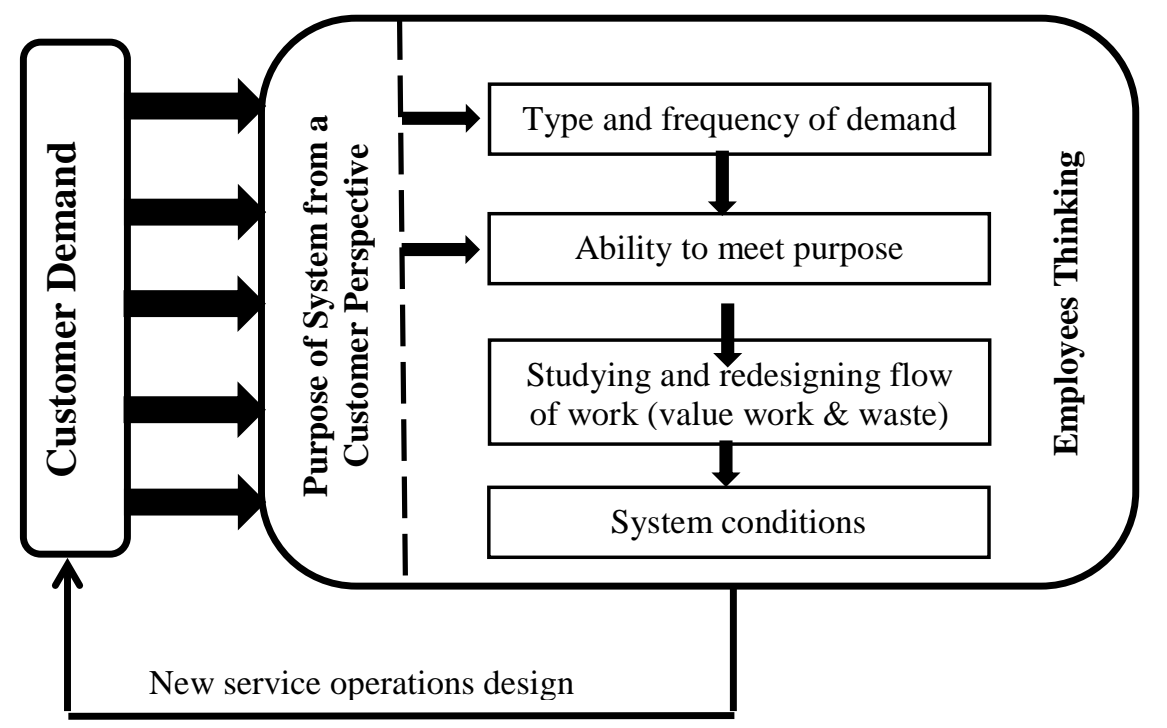

Figure 1. Conceptual framework of the Vanguard Method.

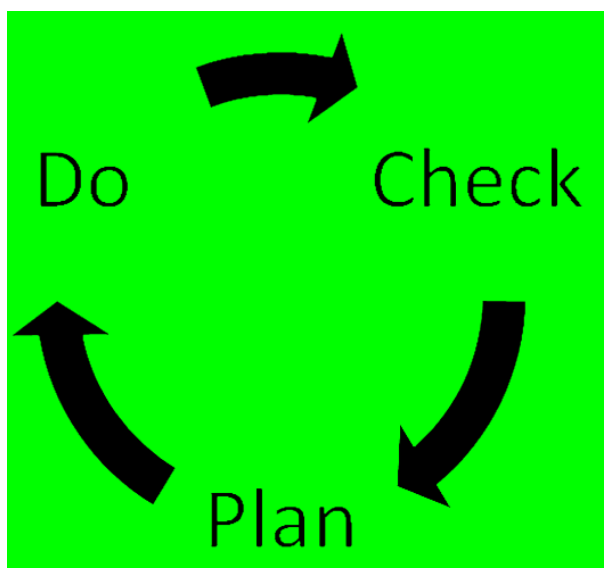

Figure 2. Check-Plan-Do cycle. 


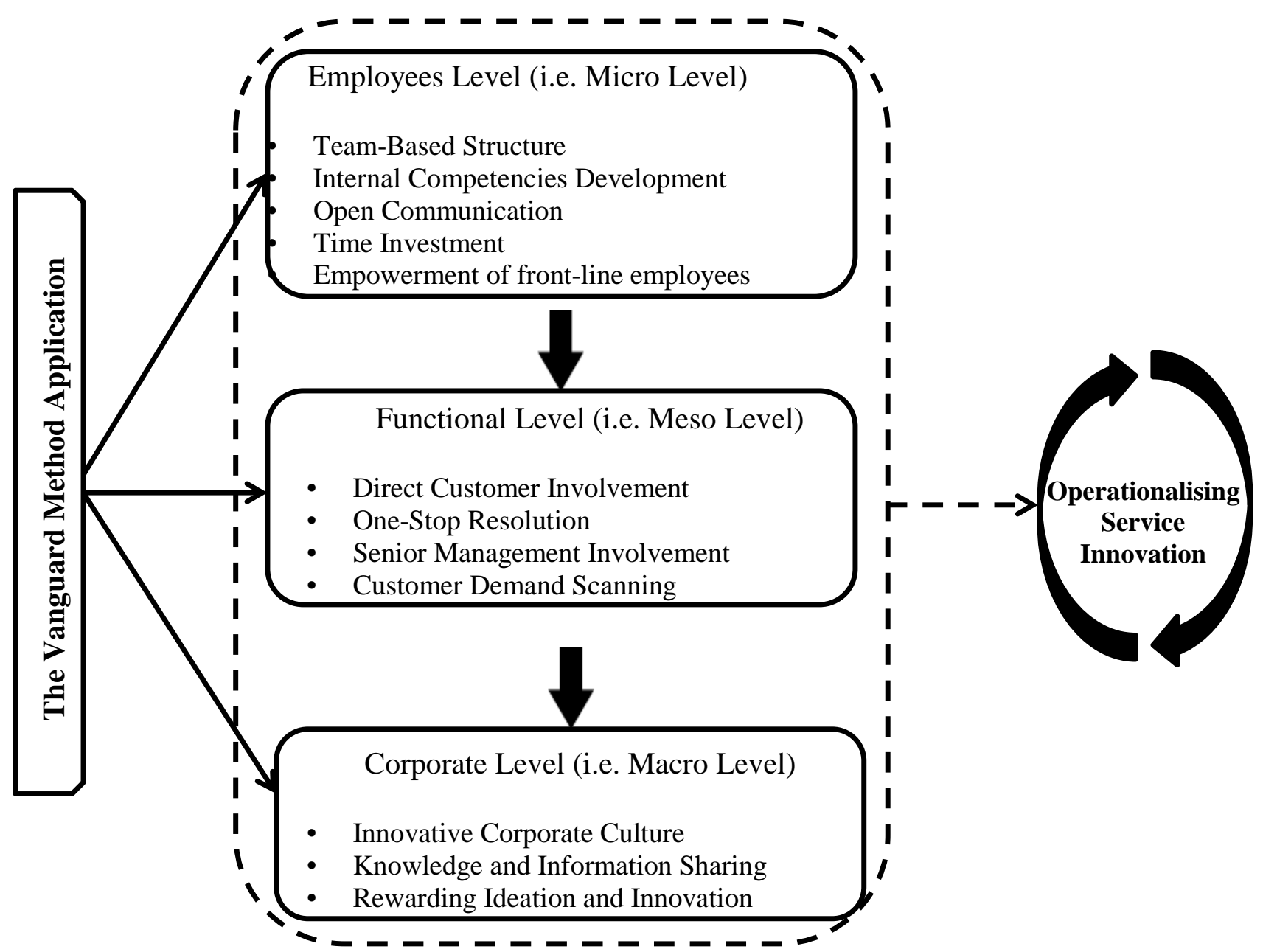

Figure 3. Three-level conceptual model for operationalising service innovation 
Table 1 case study organisations and their details.

\begin{tabular}{lll}
\hline \hline Item & Case A & Case B \\
\hline Core Business & Insurance Products & Public Services \\
Typical Services & Home, motor, pet, protection & Adults' social care, Police, \\
& claims, travel, life, and other & Children care, Housing, \\
& insurance services. & Domestic Abuse, Anti-Social \\
Location & England, UK & England, UK \\
Size & Approx. 1700 employees & Approx. 2400 employees \\
The Vanguard & Early 2015; covered home & Early 2014; covered all \\
Method Application & insurance department & departments. \\
Recent Key Service & Home insurance redesign & Integration of all services \\
Innovation & & \\
\hline \hline
\end{tabular}


Table 2. Micro-determinants of service innovation practiced in case organisations

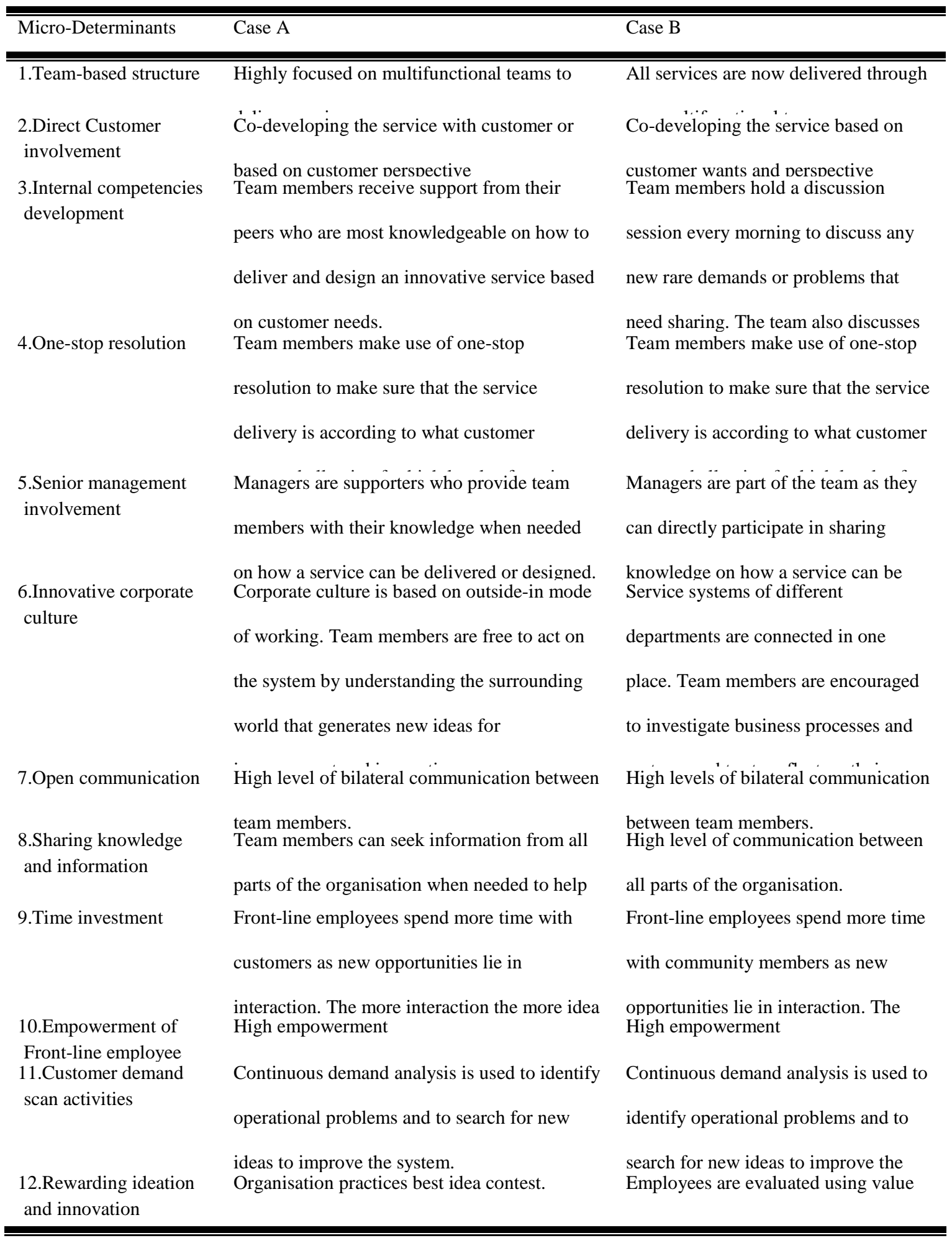


Table 3. Multilevel micro-determinants for service innovation

\begin{tabular}{lc}
\hline \hline Micro-Determinants & Organisational Structure Level \\
\hline \hline 1.Team-based structure & Employee level- Micro Level \\
3.Internal competencies development & \\
7.Open communication & \\
9.Time investment & \\
10.Empowerment of Front-line employee & \\
& \\
2. Direct Customer involvement. & Functional level- Meso Level \\
4. One-stop resolution & \\
5. Senior management involvement & \\
11. Customer demand scan activities & \\
6. Innovative corporate culture. & Corporate level- Macro Level \\
8. Sharing knowledge and information. & \\
12. Rewarding ideation and innovation & \\
\hline \hline
\end{tabular}

